\title{
Subcloud-Layer Feedbacks Driven by the Mass Flux of Shallow Cumulus Convection over Land
}

\author{
Bart J. H. VAn Stratum* AND Jordi Vilá-Guerau de AREllano \\ Meteorology and Air Quality Section, Wageningen University, Wageningen, Netherlands \\ Chiel C. VAN HeERwaARden \\ Max Planck Institute for Meteorology, Hamburg, Germany \\ HuUg G. OUWERSLOOT \\ Meteorology and Air Quality Section, Wageningen University, Wageningen, Netherlands, \\ and Max Planck Institute for Chemistry, Mainz, Germany
}

(Manuscript received 28 June 2013, in final form 18 November 2013)

\begin{abstract}
The processes and feedbacks associated with the mass flux of shallow cumulus clouds over land are studied by analyzing the results from large-eddy simulations and a mixed-layer model. The primary focus is to study the development of the (well mixed) subcloud layer and understand the four primary feedbacks between the subcloud-layer dynamics and cumulus mass flux. Guided by numerical experiments in large-eddy simulations that show the transition from clear to cloudy boundary layers at midlatitudes over land, the feedbacks introduced by shallow cumuli are first conceptually described. To study the complex interplay between the subcloud and cloud layer, a mixed-layer model is proposed and validated with large-eddy simulations for the Atmospheric Radiation Measurement Southern Great Plains case. The mixed-layer model is shown to identify and reproduce the most relevant feedbacks in the transition from clear to cloudy boundary layers: a reduced mixed-layer growth and drying of the subcloud layer by enhanced entrainment and mass flux transport of moisture to the cloud layer. To complete the study, the strength of the different feedbacks is further quantified by an analysis of the individual contributions to the tendency of the relative humidity at the top of the mixed layer.
\end{abstract}

\section{Introduction}

Shallow cumulus $(\mathrm{SCu})$ convection is a frequently observed phenomenon over land, with an average daytime occurrence of about $30 \%$ in the tropics and northern midlatitudes (June-August) as shown in Fig. 1. In addition to their importance to, for example, Earth's radiation budget, $\mathrm{SCu}$ clouds directly influence the dynamics of the well-mixed (subcloud) layer (Emmitt

\footnotetext{
* Current affiliation: Max Planck Institute for Meteorology, International Max Planck Research School on Earth System Modelling, Hamburg, Germany.

Corresponding author address: Bart van Stratum, Max Planck Institute for Meteorology, Bundesstraße 53, 20146 Hamburg, Germany.

E-mail: bart.vanstratum@mpimet.mpg.de
}

1978; Nicholls and LeMone 1980). As this layer plays an important role in, for example, the regulation of surface evaporation (van Heerwaarden et al. 2009) and the temporal evolution of chemical reactants (Vilà-Guerau de Arellano et al. 2011), it is important to obtain a thorough understanding of the influence of clouds on the temporal evolution of the subcloud-layer dynamics and the feedbacks involved in this coupled system.

Shallow cumulus convection is initiated by processes at the (land) surface, driving convection and the development of the well-mixed (subcloud) layer (e.g., Bunker 1952; Stull 1985). With an average relative humidity below $100 \%$ at the mixed-layer top or cloud base, only the strongest and moistest updrafts are able to reach their saturation level, which causes the typical patchy cloud distribution. Air parcels that rise above their level of free convection gain buoyancy through the release of latent heat, accelerate upward until they reach 


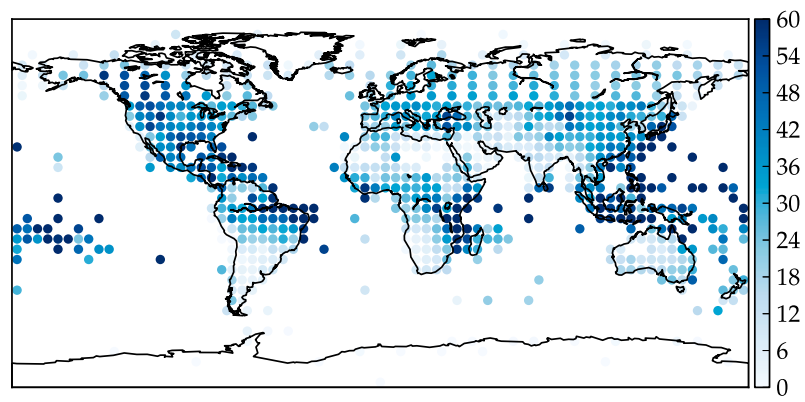

FIG. 1. Average daytime occurrence (\%) of shallow cumulus convection over land during June-August (26-yr average). Data obtained from Warren and Hahn (2010).

their level of neutral buoyancy, and form a cloud layer. This transport of mass to the cloud layer decreases the growth of the mixed layer (Stull 1988; Stevens 2007) and thereby reduces the absolute temperature and mixedlayer top relative humidity tendencies, resulting in a negative feedback on the formation of cumuli (Neggers et al. 2006). This mechanism is, however, only one direct influence. Subsequent processes and feedbacks, related to modification of the thermodynamic characteristics of the subcloud layer, further control the coupled dynamics of the subcloud and cloud layer. Although some of these feedbacks have been addressed before (the ventilation of air into the cloud layer; e.g., Stull 1985; Neggers et al. 2006), a complete conceptual framework outlining these processes and feedbacks for continental SCu-topped boundary layers in a transient setting is still missing. The first aim of this paper is to develop such a framework.

To reach this objective, we study a series of observed cases of $\mathrm{SCu}$ convection over land: the Atmospheric Radiation Measurement Southern Great Plains (ARM; Brown et al. 2002) case, Small Cumulus Microphysics Study (SCMS; Neggers et al. 2003) and Gulf of Mexico Atmospheric Composition and Climate Study (GoMACCS; Angevine et al. 2010), using large-eddy simulation (LES), with additional experiments for the $\mathrm{ARM}$ case using a mixed-layer model. LES is frequently employed to study atmospheric processes (e.g., Stevens et al. 2001; Brown et al. 2002; Siebesma et al. 2003; vanZanten et al. 2011, focusing on SCu). To complement these studies, it is convenient to develop conceptual models to study the complete parametric space of the system and its processes (e.g., Ek and Holtslag 2004; van Heerwaarden et al. 2009; Vilà-Guerau de Arellano et al. 2012) and to determine the reliability of empirical or simplified physical assumptions. While this type of model has been employed frequently to study a variety of processes in the dry convective boundary layer (e.g., de Bruin 1983; Vilà-Guerau de Arellano et al. 2011; Ouwersloot et al. 2012) or the marine cloud-topped boundary layer [e.g., Albrecht et al. 1979; Betts and Ridgway 1989; Stevens 2007; see Stevens (2006) for an overview], the application for cloud-topped continental conditions has been restricted to the onset of clouds (Findell and Eltahir 2003), indicators describing the potential of cloud formation (Ek and Mahrt 1994; Zhu and Albrecht 2002; Vilà-Guerau de Arellano 2007), or hypothetical daily-averaged equilibrium conditions (Betts 2000; Betts and Chiu 2010). The model assumptions that are typically used for marine cases [steadystate conditions (e.g., Betts and Ridgway 1989) or a mixing-line approach for the cloud layer (e.g., Neggers et al. 2006)] are invalid for continental cases characterized by strongly time-varying conditions. As such, a different approach is needed in order to represent continental cumulus-topped cases.

Recent work on this subject was done by Gentine et al. (2013), who developed a six-layer bulk model to represent cases with $\mathrm{SCu}$ convection. Here, we opt for a simpler approach. Our second aim, closely connected with the development and discussion of a conceptual framework to explain the role of mass flux in the subcloud layer, is the development of a mixed-layer (subcloud) model. By extending previous work from Tennekes and Driedonks (1981) and Neggers et al. (2006) with simple parameterizations based on experiments of the ARM, SCMS, and GoMACCS cases in LES, we propose an extension that includes the essential components needed to reproduce the subcloud-layer development for continental cases. Subsequently, this model is used to reproduce the processes and feedbacks for the ARM case.

The remainder of this paper is structured as follows: In section 2 we introduce the feedbacks between the subcloud and cloud layers, constructing a conceptual diagram that describes the role of the mass flux in the development of the subcloud layer. In section 3 we study the relevant processes in LES, derive the necessary parameterizations, and use them to construct the mixed-layer model. In section 4 this model is first validated with LES of the ARM case, and further explored by performing sensitivity experiments inspired by this case. Secondly, using the processes and feedbacks introduced in section 2 as a road map, the mixed-layer budgets of key mixed-layer variables are studied in more detail. Finally, section 5 addresses the strength and onset of the individual feedbacks by explicitly calculating their contributions to the evolution of the relative humidity at the mixed-layer top.

\section{Feedbacks in the shallow cumulus-topped convective boundary layer}

Figure 2 shows the convective boundary layer (CBL) and the main variables under study. We investigate the 


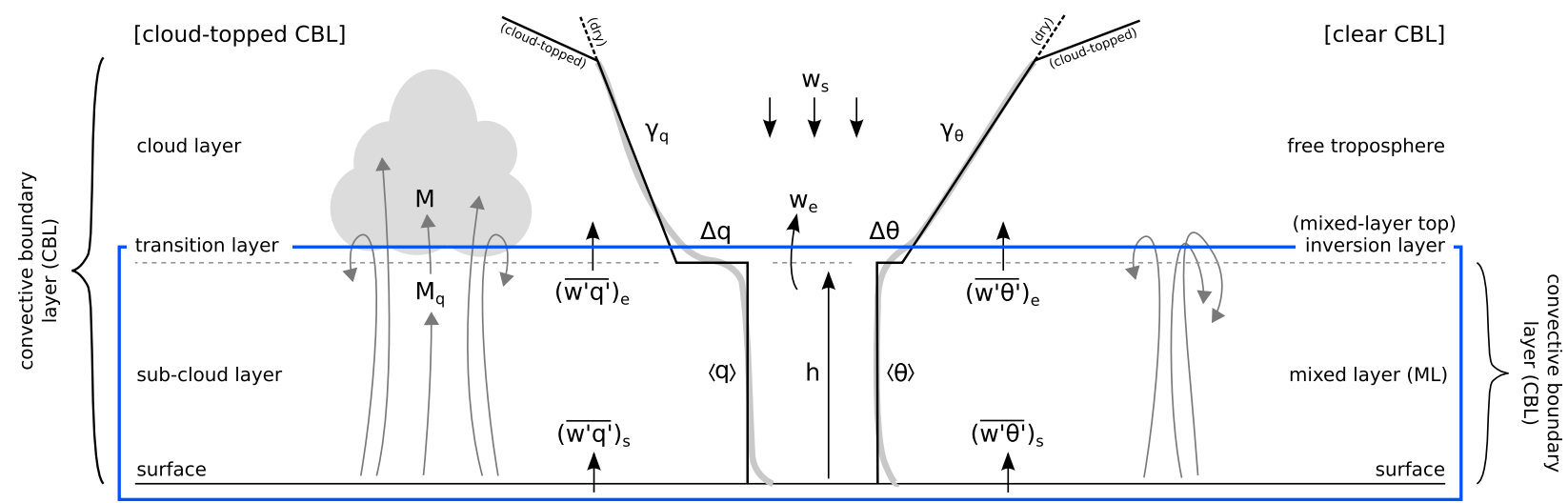

FIG. 2. Conceptual representation of both the clear and cloud-topped CBL. Compared to the clear CBL, cumulus convection introduces the mass flux $M$ and its associated moisture transport $M_{q}$ to the system. The blue box denotes the main area that we are studying.

transition of the clear to cloudy boundary layer and treat the cloud-topped CBL as an extension of the dry CBL, thus focusing on the area contained within the blue box. Both types of boundary layers have many similarities: a well-mixed layer topped by a stable (warm and dry) inversion layer, underneath a stable (or conditionally unstable) free troposphere or cloud layer. Although it might be expected that the formation of clouds at the top of the mixed layer influences entrainment, several studies found remarkably similar mixed-layer-top entrainment ratios for both the dry and cloud-topped CBL (Nicholls and LeMone 1980; Grant 2001; Grant and Lock 2004; Grant 2006).

The primary influence of cumulus convection on the mixed-layer development takes place at the top of this layer, where the convective mass flux transports air from the subcloud to the cloud layer (Betts 1973; Neggers et al. 2006). This introduces a transport term in the mixed-layer mass budget, of which the resulting feedbacks are shown in Fig. 3. We postulate that four feedback loops, all negative, control the mass flux and its influence on the dynamic evolution of the state variables in the subcloud layer:

- Feedback 1 is the "moisture variance" feedback. The horizontal fraction of the mixed-layer top that saturates depends on the mixed-layer-top relative humidity (or saturation deficit) and the spatial distribution of moisture $\sigma_{q ; h}^{2}$; (e.g., Cuijpers and Bechtold 1995). Once active clouds (cloud-core fraction $a_{\mathrm{cc}}$ ) transport mass $M$ to the cloud layer, the mixed-layer $(h)$ growth is reduced. Because as a first approximation the moisture variance scales proportional to the mixedlayer height (Neggers et al. 2007), this reduces the tendency of the moisture variance, forming a negative feedback on the formation of clouds.

- Feedback 2 is the "temperature" feedback. A second influence of the decreased mixed-layer growth rate is that the absolute temperature at $h\left(T_{h}\right)$ remains higher (Ek and Mahrt 1994), resulting in a reduced relative humidity at that height $\left(\mathrm{RH}_{h}\right)$. This has a negative impact on $a_{\mathrm{cc}}$, leading to a negative feedback on $M$.

- Feedback 3 is the "drying" feedback. As the air that is transported to the cloud layer is relatively moist, the mass flux causes a net transport of moisture $M_{q}$ to the cloud layer (Nicholls and LeMone 1980), leading to a decrease of the average mixed-layer specific humidity $\langle q\rangle$. As a result $\mathrm{RH}_{h}$ and therefore $a_{\mathrm{cc}}$ diminishes, forming the third negative feedback on $M$.

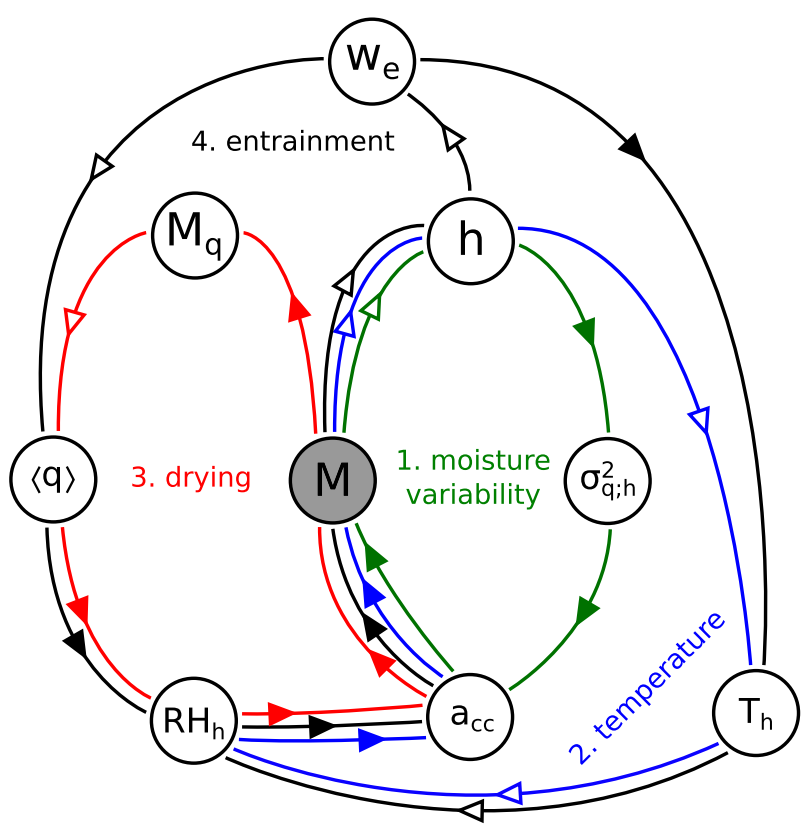

FIG. 3. Feedbacks between the (well mixed) subcloud and cloud layer associated with the dynamics of SCu convection. Solid arrows denote a positive feedback and open arrows denote a negative feedback. 
- Feedback 4 is the "entrainment" feedback. A direct result of the reduced mixed-layer growth is a reduced rate of increase of the mixed-layer-top discontinuities of temperature and moisture, as is typically observed in cases with $\mathrm{SCu}$. As this reduces the mixed-layer-top inversion strength, the entrainment velocity and fluxes increase, adding a heating and drying tendency to the mixed layer, which further strengthen feedbacks 2 and 3.

Summarized, the direct result of these feedbacks is drying of the mixed layer and a reduced mixed-layer growth. Also, as the cloud (core) fraction depends on the relative humidity, feedbacks $2-4$ strongly modulate the relative humidity evolution in order to maintain the typical small SCu fraction. Although Fig. 3 only focuses on processes that are unique for cloud-topped CBLs, more feedbacks that are common for the CBL in general are to be expected. Our objective of the next sections is to quantify and verify these additional feedbacks, as well as the ones presented in Fig. 3, with help of a mixed-layer model. The model is designed with help of three observed cases of shallow cumulus, studied with the Dutch Atmospheric LES (DALES 3.2; Heus et al. 2010), and validated for the ARM case.

\section{Description conceptual model}

This section describes the minimal model needed to reproduce the processes and feedbacks that govern the $\mathrm{SCu}$-topped CBL. Although clouds play a crucial role in Earth's radiation budget (Stokes and Schwartz 1994) and the link between atmospheric water and circulation patterns (Stevens and Bony 2013), we follow previous authors (e.g., Neggers et al. 2006) in applying a minimal approach by modeling the cloud layer as a boundary condition for the well-mixed layer. The implications of neglecting the cloud-layer development are discussed at the end of this section.

The starting point for our conceptual model is the mixed-layer model of Betts (1973), Carson (1973), and Tennekes (1973), using the Boussinesq approximation (like in LES). As it is well documented in a number of papers (e.g., Tennekes and Driedonks 1981), we limit the description to the additional representations needed to take $\mathrm{SCu}$ convection into account. Unless stated otherwise, the equations for bulk-averaged scalars (both Reynolds averaged and averaged over the mixed-layer depth $\langle\phi\rangle)$, mixed-layer-top discontinuities $\Delta \phi$, mixedlayer height $h$, entrainment fluxes $\left(\overline{w^{\prime} \phi^{\prime}}\right)_{e}$, and entrainment velocity $w_{e}$ are similar to those listed in van Stratum et al. (2012). In addition to the description of the model dynamics, we include a validation of the key assumptions based on LES experiments.

\section{a. Extension to clouds: Dynamics}

To include the influence of clouds on the mixed-layer continuity equation, we follow Betts (1973), Stull (1985), and Neggers et al. (2006) by adding a mass flux term to the prognostic equation for the mixed-layer height. This term accounts for the transport of air mass from the subcloud to the cloud layer (Fig. 2):

$$
\frac{d h}{d t}=w_{e}+w_{s}-M
$$

where $w_{e}$ and $w_{s}$ represent the entrainment and subsidence velocities, respectively. Throughout the remainder of this paper, $w_{s}$ is assumed to be zero. We employ the same relation for estimating the entrainment velocity as for the dry CBL [i.e., $w_{e}=-\left(\overline{w^{\prime} \theta_{v}^{\prime}}\right)_{e} / \Delta \theta_{v}$ ]. The reliability of this assumption, and the influence on the entrainment fluxes in this transient CBL, is further validated in the next section. The term $M$ denotes the kinematic mass flux (i.e., the mass flux divided by the air density) of air being transported by clouds from the subcloud to cloud layer. Following (Neggers et al. 2004, 2006), this term is modeled as

$$
M=a_{\mathrm{cc}} w_{\mathrm{cc}},
$$

where $a_{\mathrm{cc}}$ and $w_{\mathrm{cc}}$ stand for the maximum cloud-core fraction and its corresponding vertical velocity at that height, respectively. Although the mixed-layer top and height of the maximum cloud-core fraction usually differ, this difference is typically small, and it is assumed that the area fraction and velocity are constant over this layer. By using cloud-core properties (sampled at locations where positively buoyant clouds are present; Siebesma et al. 2003), we ensure that only transport by the active part of the cloud is taken into account. Using results from DALES, we show in Fig. 4a that the cloudcore velocity scales well with the convective velocity scale $w_{*}$, with the inclusion of a prefactor $\lambda \approx 0.84$ :

$$
w_{\mathrm{cc}} \approx \lambda w_{*}=\lambda\left[\frac{g h\left(\overline{w^{\prime} \theta_{v}^{\prime}}\right)_{s}}{\left\langle\theta_{v}\right\rangle}\right]^{1 / 3}
$$

This relation builds on Neggers et al. (2004, 2006), who did not include $\lambda$, and is confirmed by Ouwersloot et al. (2014). Also, with a typical cloud-core fraction of $4 \%-5 \%$ and $w_{*}$ on the order of $1 \mathrm{~m} \mathrm{~s}^{-1}$, these findings corroborate the approach of Grant (2001), who modeled the mass flux as $M=0.03 w_{*}$. We employ the relationship in Eq. (3) to model $w_{\mathrm{cc}}$ in Eq. (2). The horizontal fraction of the mixed layer that reaches the lifting condensation level (LCL) is estimated with knowledge of 

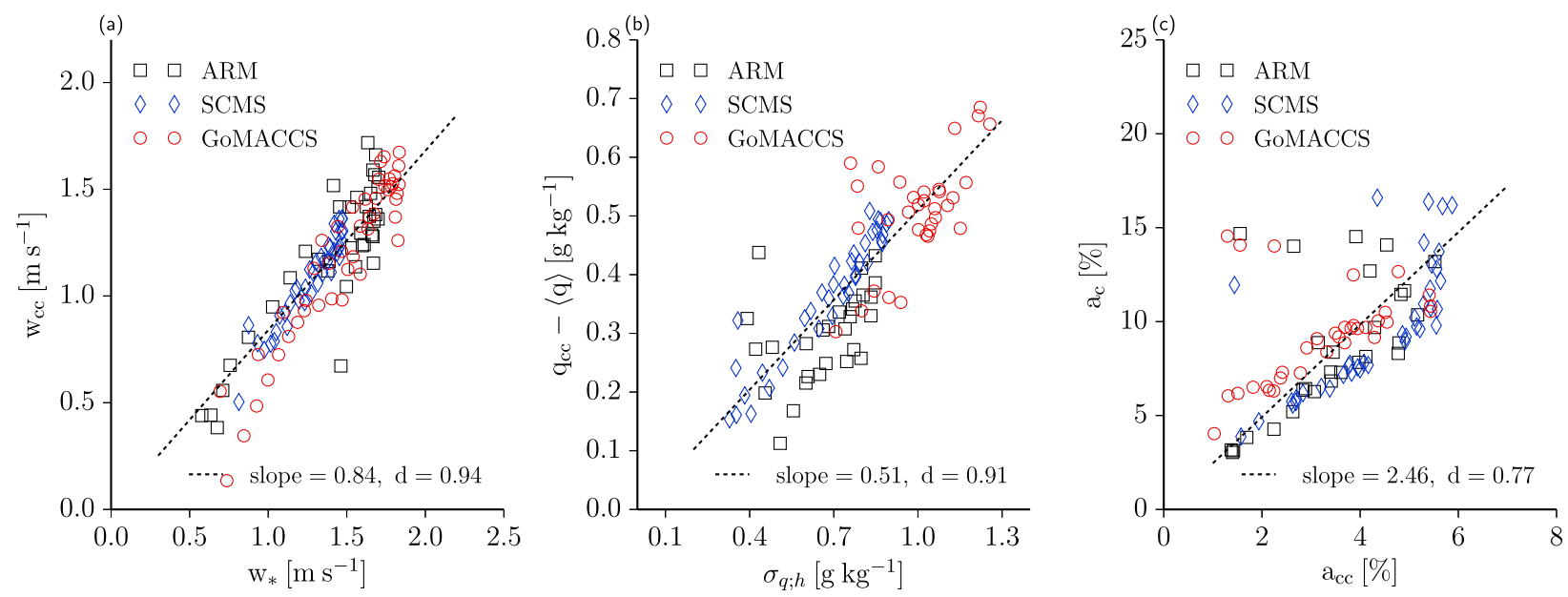

FIG. 4. Scaling of (a) the cloud-core velocity at the height of the maximum cloud-core fraction as a function of $w_{*}$, (b) the moisture excess of the cloud core over the slab-averaged value vs the mixed-layer-top standard deviation, and (c) the total fractional cloud coverage as a function of the cloud-core fraction. Indicator " $d$ " is the "index of agreement" (Willmott 1981).

both the average saturation deficit and the spatial moisture distribution at the mixed-layer top (Cuijpers and Bechtold 1995; Neggers et al. 2006):

$$
a_{\mathrm{cc}}=0.5+\alpha \arctan \left(\eta \frac{\langle q\rangle-\bar{q}_{s ; h}}{\sigma_{q ; h}}\right),
$$

where $\bar{q}_{s ; h}$ and $\sigma_{q ; h}$ are the saturation specific humidity and specific humidity variance at the mixed-layer top, respectively. The constants $\alpha=0.36$ and $\eta=1.55$ are adapted to fit this function to LES results in order to remove passive cloudiness (Neggers et al. 2006). Validation of this parameterization using LES of the ARM, SCMS, and GoMACCS cases showed a satisfactory agreement between the modeled and observed cloud-core fraction (not shown). This indicates that the parameterization also holds for continental, non-steady-state cases.

\section{b. Extension to clouds: Mixed-layer budgets}

As introduced in section 2, the mass flux also directly influences the subcloud-layer budget of heat, moisture, and other scalars, as it transports air with updraft properties from the subcloud to the cloud layer. We account for this transport by adding an additional term $\left(M_{\phi}\right)$ to the mixed-layer budget equation:

$$
\frac{d\langle\phi\rangle}{d t}=\frac{\left(\overline{w^{\prime} \phi^{\prime}}\right)_{s}-\left(\overline{w^{\prime} \phi^{\prime}}\right)_{e}-M_{\phi}}{h} .
$$

An advective term has been omitted from this equation but can easily be added as a source tendency. The mass flux term is modeled similar to the mass flux approach in, for example, single-column models (SCM; e.g., Siebesma et al. 2007). However, as shown in the derivation in appendix $\mathrm{A}$, the resulting term in the budget equations acts on the difference between updrafts and the bulk-averaged mixed-layer values $\langle\phi\rangle$, rather than Reynolds-averaged values $\bar{\phi}$ :

$$
M_{\phi}=M\left(\phi_{\mathrm{cc}}-\langle\phi\rangle\right) .
$$

This term $\left(M_{\phi}\right)$ only accounts for the additional influence of mass flux transport on the budget of $\langle\phi\rangle$ and is typically smaller than the total mass flux transport that governs the flux in the cloud layer [expressed by $\left.M\left(\phi_{\mathrm{cc}}-\bar{\phi}\right)\right]$. See Ouwersloot et al. (2014) for a discussion on the difference between these mass flux definitions. It is important to stress that, by splitting the total mixed-layer-top flux, we individually model the contribution by entrainment (driven by dry convection) and mass flux transport (moist convection). The updraft (or cloud core $\phi_{\mathrm{cc}}$ ) properties are typically estimated using an entraining-plume model. Here we adopt a different strategy by relating $\phi_{\mathrm{cc}}-\langle\phi\rangle$ to the mixed-layer-top variance. We limit this relation to moisture, as analysis of LES data has shown that, because of lateral entrainment into the updraft and the positive temperature gradient at the mixed-layer top, $\phi_{\mathrm{cc}}-\langle\phi\rangle$ is close to zero for the potential temperature [similar behavior was reported by Nicholls and LeMone (1980)]. However, as demonstrated by Ouwersloot et al. (2014), this relation can be extended to other scalars.

Figure $4 \mathrm{~b}$ shows the relation between $\sigma_{q ; h}$ and $q_{\mathrm{cc}}-\langle q\rangle$. With the inclusion of a prefactor $\varphi \approx 0.51$, there is a satisfactory agreement between both quantities:

$$
\phi_{\mathrm{cc}}-\langle\phi\rangle \approx \varphi \sigma_{q ; h} .
$$


Using this relation, we can extend the budget of moisture to include the influence of mass flux transport as

$$
\frac{d\langle q\rangle}{d t}=\frac{\left(\overline{w^{\prime} q^{\prime}}\right)_{s}+w_{e} \Delta q-M \varphi \sigma_{q ; h}}{h} .
$$

As discussed in section 2, this contributes to the negative feedbacks as clouds dry the mixed layer. Interestingly, for the conditions considered in this study (small cloud fractions), there is also a relation between the cloud-core and total cloud fraction, as shown in Fig. $4 c$. This relation might be useful as a first estimate for the cloud fraction when radiative processes (e.g., shortwave incoming radiation or photolysis rates) are considered.

To close this minimal model for the representation of $\mathrm{SCu}$ at the mixed-layer top, the local specific humidity variance is modeled using a diagnostic equation (Neggers et al. 2007). Under the assumption that local changes in the storage of variance $\left(d \sigma_{q ; h}^{2} / d t\right)$ are small, and that the production of variance (transport of relatively moist air by thermals into the moisture gradient at the mixed-layer top) is balanced exactly by vertical transport and dissipation, the moisture variance budget reads

$$
\sigma_{q ; h}^{2} \approx-\left(\overline{w^{\prime} q^{\prime}}\right)_{h} \frac{\Delta q}{\Delta z} \frac{h}{w_{*}},
$$

where $\left(\overline{w^{\prime} q^{\prime}}\right)_{h}$ is the total moisture flux at $h$ (entrainment + mass flux transport) and $\Delta z$ is a depth that describes the thickness of the transition layer from dry to moist convection. Note that the inclusion of the total moisture flux introduces a dependence where the variance calculated in Eq. (9) depends on the moisture mass flux [Eq. (6)], which [through our parameterization described in Eq. (7)] depends on the variance itself. We iterate this set of equations to a converged solution. Analysis using LES of the ARM, SCMS, and GoMACCS cases showed that, despite the transient characteristics of the cases, $\Delta z$ is relatively constant throughout the day (in between 100 and $200 \mathrm{~m}$ for all cases, with temporal changes on the order of $50 \mathrm{~m}$ ). Nonetheless, once clouds have formed, we nudge $\Delta z$ toward its thickness as defined by Neggers et al. (2006) $\left(\Delta z=z_{\mathrm{lcl}}-h\right)$ on a mixed-layer turnover time scale $\tau=h / w_{*}$.

\section{c. Limitations of our conceptual model}

Not representing the evolution of the cloud-layer dynamics directly influences the mixed-layer model, as clouds typically decrease the temperature and moisture lapse rates $\left(\gamma_{q}\right.$ and $\gamma_{\theta}$; Fig. 2) in the lower part of the cloud layer. Although this has an impact on the development of the mixed-layer-top jumps (indirectly affecting the complete mixed layer), this influence is largely canceled by the reduced mixed-layer growth after the formation of clouds. However, in order to investigate the impact of the cloud layer on our assumptions, we analyze and discuss the evolution of the mixed-layer-top jumps in the next section.

\section{Results}

\section{a. Subcloud-layer dynamics: LES versus mixed-layer model}

We start our validation of the previously described mixed-layer model (MXL) with results from LES. Because of the early onset of clouds in both the SCMS and GoMACCS cases (less than $1.5 \mathrm{~h}$ after the start of the experiment), we limit the validation to the ARM case. This is the only case with a substantial period of dry convection after the spinup of LES - necessary to study the transition from dry to $\mathrm{SCu}$ convection. To quantify the impact of $\mathrm{SCu}$ formation and the capabilities of MXL to reproduce the transition from clear to cloudy boundary layers, we performed two additional experiments where either the specific humidity is decreased to prevent the formation of clouds (ARM-clear) or $M$ (and therefore $M_{\phi}$ ) is set to zero (ARM-nc). In doing so, the mixed-layer model reduces to the original formulation of Tennekes and Driedonks (1981). The initial and boundary conditions used in MXL and LES are described in appendix B.

As shown in Fig. 5a, the mixed-layer height in MXL displays a satisfactory agreement with the tendency found in LES, where the latter is defined as the height of the minimum buoyancy flux. After the onset of clouds around 1700 UTC (Fig. 5b), mass flux transport becomes active and the height tendency decreases as discussed in Fig. 3. The overestimation of the mixed-layer height in MXL is caused by a small delay in the onset of $\mathrm{SCu}$, and the slight underestimation of the cloud-core fraction between 1830 and 2000 UTC. After 2000 UTC the mixed-layer height tendency in MXL agrees with LES, but the small discrepancy in height between MXL and LES remains. Although the bulk potential temperature (Fig. 5c) is not directly influenced by mass flux transport ( $M_{\theta}$ is fixed at zero in our model, which is justified in the discussion of Fig. 6), the temporal evolution differs between both cases owing to the reduced mixed-layer growth. Both the lower mixed-layer height (reducing the mixing depth of any input or loss of heat at the surface or mixed-layer top) and increased entrainment velocity result in an increased tendency of $\langle\theta\rangle$. This is a first indication of the importance of correctly representing the mixed-layer height in the budget equations of scalars. 

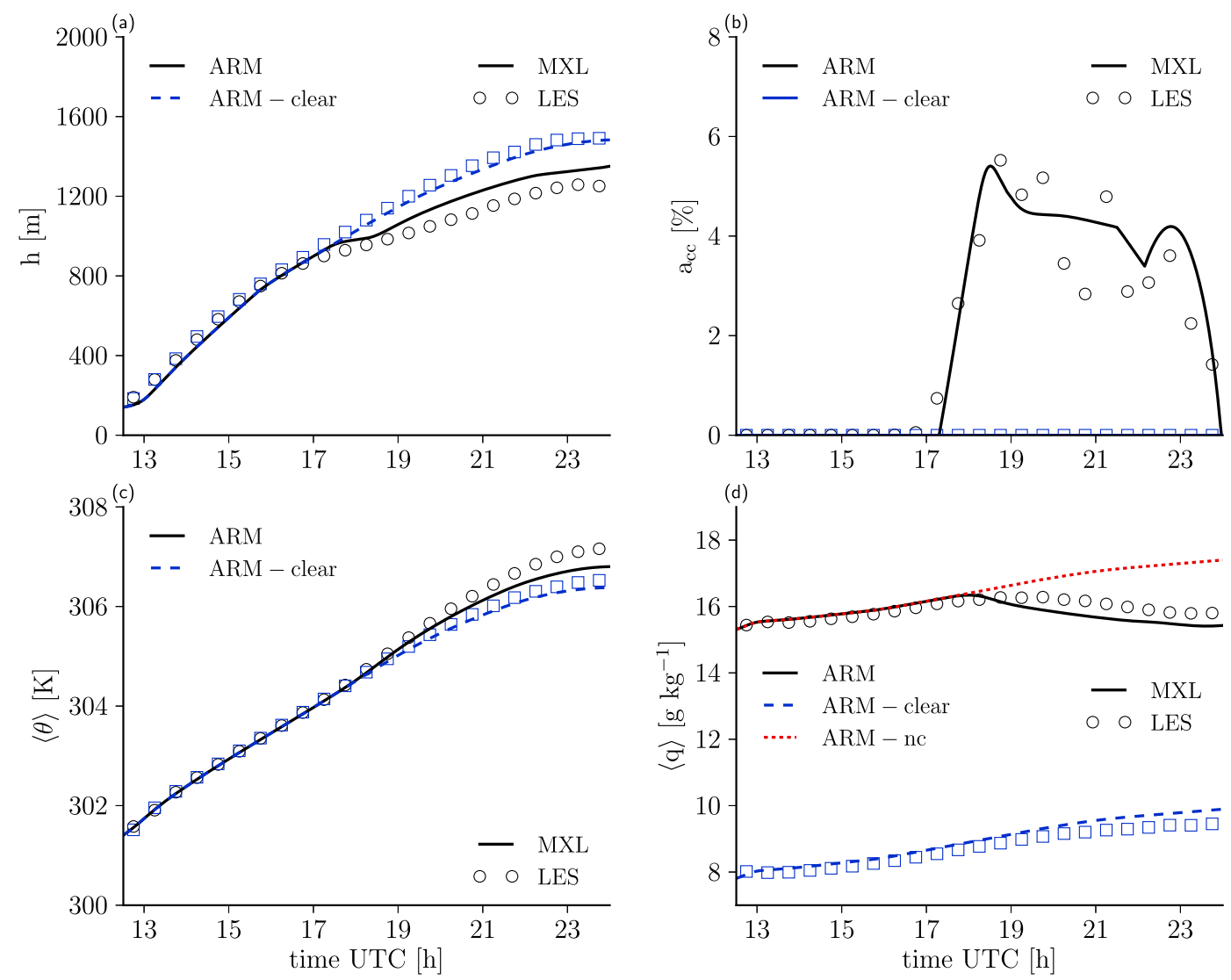

FIG. 5. Temporal evolution of (a) mixed-layer height, (b) cloud-core fraction, (c) bulk potential temperature, and (d) bulk specific humidity mixing ratio. Case ARM-nc represents a case in which the SCu parameterization has been disabled, reverting MXL to the original model of Tennekes and Driedonks (1981). Lines (solid and dashed) represent the results in MXL and symbols (circles and squares) represent LES data.

A similar process is acting on the evolution of the bulk specific humidity (Fig. 5d). However, with a positive flux at both the surface $\left[\left(\overline{w^{\prime} q^{\prime}}\right)_{s}\right]$ and mixed-layer top $\left[\left(\overline{w^{\prime} q^{\prime}}\right)_{e}\right]$ and the addition of mass flux transport $M_{q}$, the interpretation is less straightforward. Both the entrainment and moisture mass flux cause a drying tendency, which is increased compared to the dry case by the addition of the mass flux (feedback 3) and increased entrainment flux (feedback 4). On the other hand, the reduced mixed-layer growth increases the tendency of $\langle q\rangle$ as the surface latent heat flux is mixed over a shallower layer. MXL correctly represents the tendency observed in LES, whereas not accounting for the influence of the mass flux [i.e., the original model of Tennekes and Driedonks (1981), case ARM-nc] would result in an overestimation of $\langle q\rangle$ of about $2 \mathrm{~g} \mathrm{~kg}^{-1}$ at the end of the experiment.

We complement the analysis by comparing the temporal evolution of these competing processes in more detail-that is, the individual contribution of the surface, entrainment, and mass flux on the budgets of $\langle\theta\rangle$ and $\langle q\rangle$ [Eq. (5)], using MXL and LES. In addition, we validate the temporal evolution of the mixed-layer-top jumps $\Delta \phi$. As mentioned in section 3c, their evolution is potentially biased by not taking into account the processes in the cloud layer. Therefore, the correct representation of $\Delta \phi$ is a crucial aspect in the parameterization of both the entrainment velocity and fluxes in MXL.

Retrieving the mixed-layer-top jumps and fluxes from LES is not straightforward. As argued by Lilly (2002), the spatial variability in the mixed-layer height makes a direct comparison between Reynolds-averaged profiles from LES and the results from MXL difficult. In addition, reconstructing the MXL profiles from LES (e.g., Conzemius and Fedorovich 2007) has proven to be sensitive to the determination of $\gamma_{\phi}$. To circumvent these problems, we analyze the mixed-layer-top fluxes and jumps using a mixed-layer model approach: First, we analyze $d\langle\phi\rangle / d t, h$, and $w_{e}$ from two consecutive output time steps from LES, with $w_{e}=d h / d t+M$ [Eq. (1), with $\left.w_{s}=0\right]$. With a prescribed surface flux and the mass flux transport calculated using Eq. (6), we calculate 

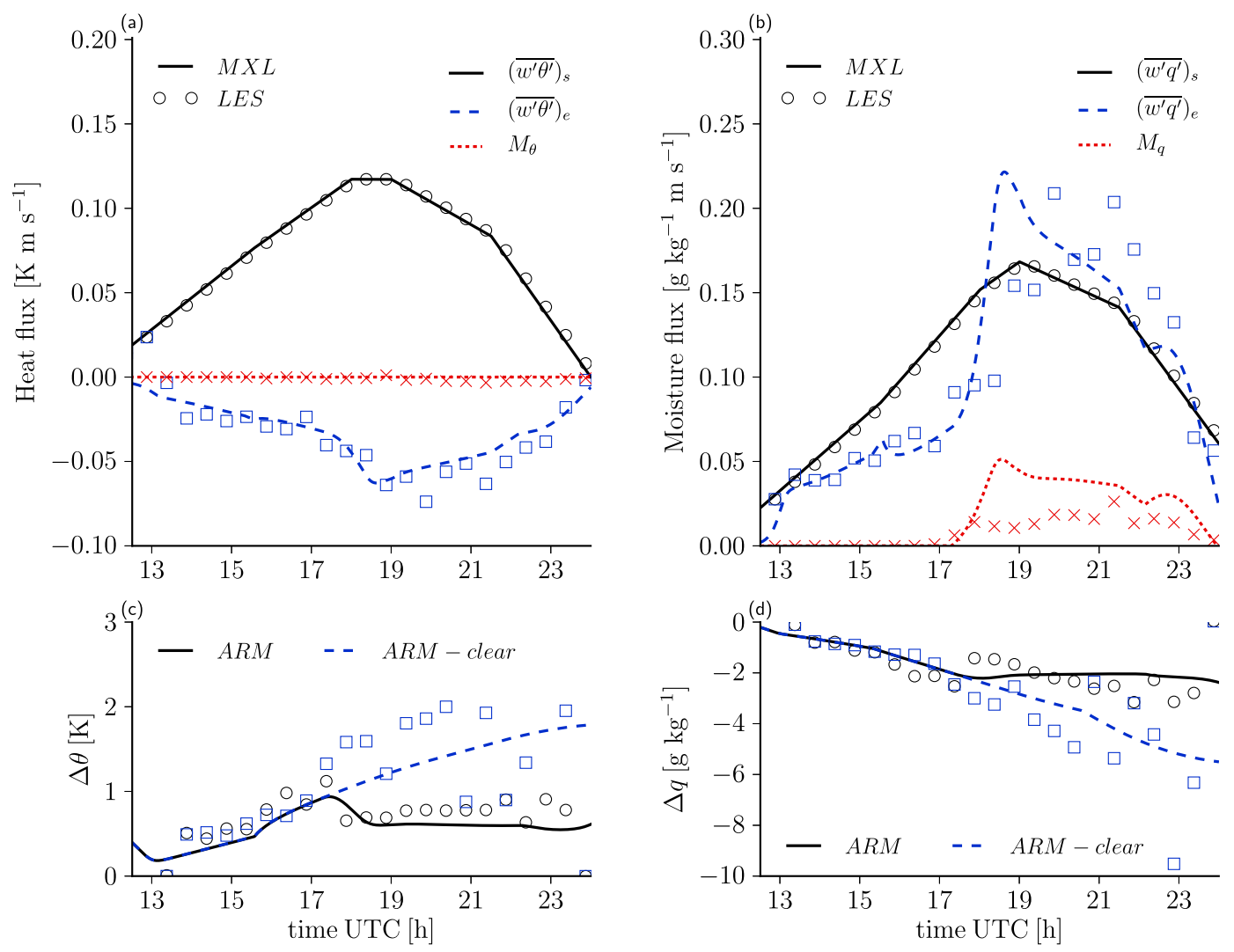

FIG. 6. Temporal evolution of the fluxes that contribute to the mixed-layer budgets of (a) heat and (b) moisture studied in more detail for the ARM case. (c),(d) Temporal evolution of the mixed-layer-top jumps for the ARM and ARM-clear cases. Lines (solid and dashed) represent the results in MXL and symbols (circles and squares) represent LES data.

$\left(\overline{w^{\prime} \phi^{\prime}}\right)_{e}$ as the transport needed to close Eq. (8). Finally, we estimate the jumps as $\Delta \phi=-\left(\overline{w^{\prime} \phi^{\prime}}\right)_{e} / w_{e}$.

Figures $6 \mathrm{a}$ and $6 \mathrm{~b}$ show the turbulent surface, entrainment, and mass fluxes of $\theta$ and $q$ for the ARM case. As both LES and MXL are forced with identical prescribed surface fluxes, we omit the discussion since this is an imposed contribution. However, future studies of $\mathrm{SCu}$ convection over land will need to determine the importance of including a coupled land surface scheme. With respect to the entrainment and mass flux of potential temperature, two interesting features can be noticed. First, as mentioned in section 3, the mass flux contribution to the budget of $\langle\theta\rangle$ is negligible. Second, there is a clear increase in the entrainment of warm (and dry) air after the formation of clouds around 1700 UTC. This is the direct result of the reduced tendency of $\Delta \theta$, as shown in Fig. 6c, and discussed earlier as the entrainment feedback in section 2. Notice that, despite the simplicity, MXL adequately represents the temporal evolution of $\Delta \theta$ and $\Delta q$. This indicates that, at the short time scales addressed in this study, the temporal evolution of $\gamma_{\theta}$ and $\gamma_{q}$ in the cloud layer (constant in time in this study) does not significantly influence our experiments. This was confirmed by a sensitivity experiment where we changed the lapse rates based on the results of LES to mimic the development of the cloud layer (not shown). With realistically changing lapse rates, $h$ changed approximately $+50 \mathrm{~m}$ and $\langle q\rangle$ changed by approximately $-0.5 \mathrm{~g} \mathrm{~kg}^{-1}$. As typically observed for cases with $\mathrm{SCu}$ convection, the mixed-layer-top jumps are significantly smaller compared to dry cases (ARM-clear).

In analyzing the moisture budget, we find that the mass flux contribution is small but more significant (of order $15 \%$ of the surface and entrainment fluxes), as shown in Fig. 6b. Note that $M_{\phi}$ only accounts for the influence of mass flux transport on the budget of $\langle\phi\rangle$ and is typically smaller than the total SCu mass flux transport (Ouwersloot et al. 2014). The small overestimation of the mass flux term in MXL is primarily caused by an overestimation of the mixed-layer-top moisture variance [Eq. (9)], used to parameterize $\phi_{\mathrm{cc}}-\langle\phi\rangle$ in Eq. (6). The fact that the overestimation of $\sigma_{q ; h}^{2}$ only has a minor influence on the CBL development is due to the four negative feedbacks discussed in section 2 , regulating the 

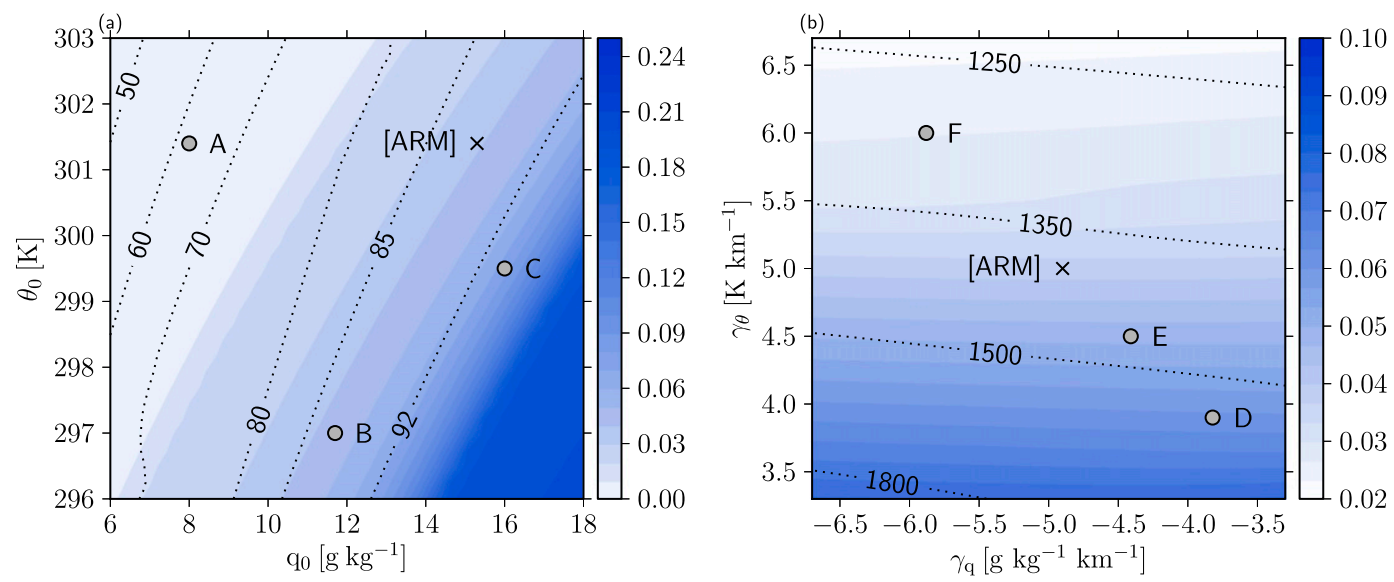

FIG. 7. Sensitivity experiment perturbing the (a) initial potential temperature and specific humidity content and (b) potential temperature and specific humidity lapse rates. Contoured in color is the average cloud-core fraction, and lines are the (a) maximum relative humidity at the mixed-layer top and (b) maximum boundary layer height.

formation of clouds and preventing, for example, excessive drying. This shows the advantage of actively integrating the mass flux in the dynamics of the CBL, instead of using a diagnostic approach.

\section{b. Exploring the shallow cumulus parameter space}

In the previous section we demonstrated that the conceptual model is able to reproduce the main subcloudlayer features of the ARM case. It is therefore interesting to further study the response of cloud characteristics (here quantified by the mass flux) in relation to the subcloud-layer dynamics (quantified by the mixed-layer height and moisture content) for a wide range of initial and boundary conditions. First, we study the sensitivity to the initial potential temperature and specific humidity content, which, together with the mixed-layer height, determines the (initial) relative humidity at the mixedlayer top. Second, we analyze the response of $M, h$, and $\langle q\rangle$ to changes in the temperature and specific humidity lapse rates above the mixed layer. Especially the potential temperature lapse rate plays a crucial role in the growth rate of the mixed layer, promoting clouds as the mixed-layer top cools (temperature feedback; section 2).

From the complete range of conditions studied with the mixed-layer model, we selected six representative states to be further studied with LES. Figure 7 shows the results of the experiments with MXL. In Fig. 7a, the sensitivity on the initial temperature and moisture content is analyzed, with the maximum (temporal) cloud-core fraction in filled contours and the maximum mixed-layer-top relative humidity contoured with lines. The cloud-core fraction and relative humidity follow the expected behavior, both increasing as temperature is reduced or as the moisture content is increased. Figure $7 \mathrm{~b}$ shows the sensitivity of the cloud-core fraction (filled contour) and mixed-layer height on the free-tropospheric lapse rates of temperature and moisture. Controls on the cloud-core fraction and mixed-layer height are largely dominated by the stability of the free troposphere, where a decrease in lapse rate promotes a faster mixed-layer growth. There is, however, a small dependency on the moisture lapse rate, as a larger (negative) lapse rate allows for the formation of larger mixed-layer-top moisture jumps, increasing the entrainment of dry air. Indicated within Fig. 7 are the conditions selected for discussion with LES. Point A is characterized by a dry $\mathrm{CBL}$, where $\mathrm{B}$ and $\mathrm{C}$ are colder and moister, resulting in the formation of clouds. For the sensitivity on the lapse rates, D, E, and F cover the regime with cumulus clouds, but with an increase in stability ranging from $\mathrm{D}$ to $\mathrm{F}$.

Figure 8 shows the comparison between MXL and LES for the mixed-layer height, bulk specific humidity, and mass flux. All experiments correctly reproduce the onset of clouds and (except for case C), the temporal evolutions of $h,\langle q\rangle$, and $M$ observed in LES. For cases A-C, the increasing mass flux causes a reduced mixedlayer growth and enhanced drying of the mixed layer. The overestimation of the mass flux in case $\mathrm{C}$ is primarily caused by an overestimation of the mixed-layertop variance using Eq. (9). For cases D-F, the increase in temperature lapse rate causes a reduced mixed-layer growth, resulting in a lower cloud fraction, mass, and entrainment fluxes and therefore less drying of the mixed layer.

Our findings show that with a physically sound parameterization for the entrainment and mass flux, we are able to represent the influence of $\mathrm{SCu}$ on the subcloud layer under a wide range of conditions. This includes the 

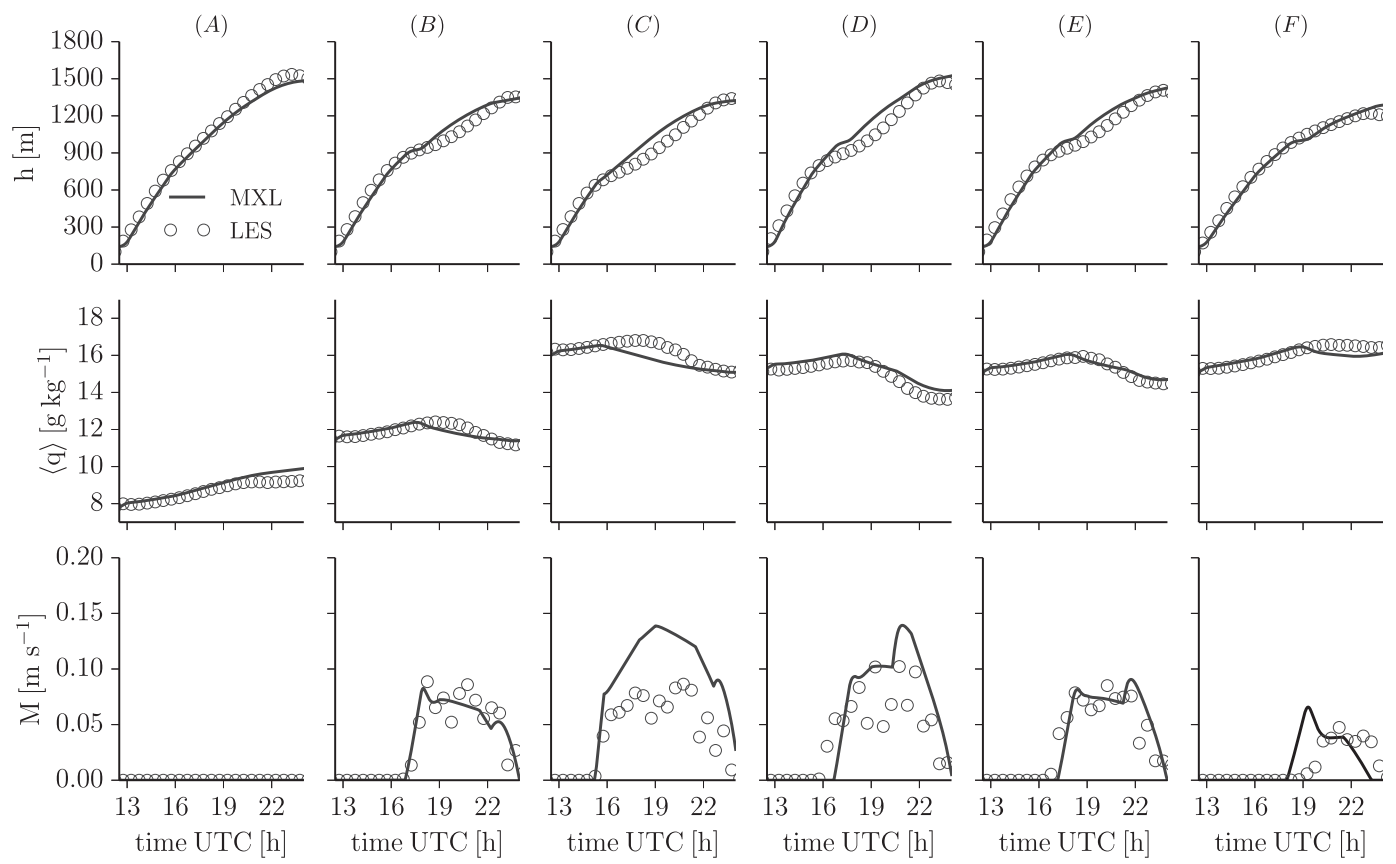

FIG. 8. Validation of the MXL results using LES for the six points selected in Fig. 7. (top) Mixed-layer height, (middle) bulk specific humidity, and (bottom) mass flux.

transition from a dry CBL to fully developed SCu convection, with characteristic potential temperature and moisture lapse rates in the free troposphere or cloud layer for both types of cases.

\section{Discussion of the feedbacks}

As shown in Fig. 3, four negative feedbacks are acting on the mass flux: three that regulate the cloud-core fraction by modulating $\mathrm{RH}_{h}$ (feedbacks 2-4), and one that regulates clouds by adjusting the mixed-layer-top moisture variability (feedback 1 ). Combined, the result of the feedbacks on $\mathrm{RH}_{h}$ is one order of magnitude stronger than those acting on $\sigma_{q ; h}^{2}$. Here we discuss the three stronger feedbacks in more detail.

One direct result of the negative feedbacks is a regulation of the mixed-layer-top relative humidity. As shown in Fig. 9a, $\mathrm{RH}_{h}$ increases with approximately $5 \% \mathrm{~h}^{-1}$ until the saturation deficit is sufficiently small to form clouds. After the formation of clouds, the negative feedbacks begin to regulate $\mathrm{RH}_{h}$, resulting in an average tendency of about zero. To further study the relative contribution of the different processes and feedbacks in more detail, we examine the tendency of the mixedlayer-top relative humidity using the prognostic equation derived by Ek and Mahrt (1994) and Chang and Ek (1996). Their formulation, which accounts for the individual contributions of mixed-layer growth and change in mixed-layer moisture content and mixedlayer-top temperature on $\mathrm{RH}_{h}$, is here further extended to quantify the influence of the mass flux on mixed-layer growth and drying. Splitting their mixed-layer growth $(d h / d t)$ and total mixed-layer-top moisture flux $\left[\left(\overline{w^{\prime} q^{\prime}}\right)_{h}\right]$ into the particular contributions by entrainment and mass flux results in

$$
\begin{aligned}
\frac{d \mathrm{RH}}{d t}= & \underbrace{C_{0}\left(\overline{w^{\prime} q^{\prime}}\right)_{s}}_{\mathrm{i}}-\underbrace{C_{0}\left(\overline{w^{\prime} q^{\prime}}\right)_{e}}_{\mathrm{ii}}-\underbrace{C_{0} M_{q}}_{\mathrm{iii}} \\
& \underbrace{-C_{1}^{*}\left[\overline{\left(\overline{w^{\prime} \theta^{\prime}}\right)_{s}}-\left(\overline{w^{\prime} \theta^{\prime}}\right)_{e}\right]}_{\mathrm{iv}} \underbrace{+C_{2}^{*} h w_{e}}_{\mathrm{v}}-\underbrace{C_{2}^{*} h M}_{\mathrm{vi}} .
\end{aligned}
$$

The parameters $C_{0}, C_{1}^{*}$, and $C_{2}^{*}$ are defined in appendix C.

Two processes govern the increase of the relative humidity: moistening of the CBL by surface evaporation (term i) and reaching higher mixed-layer heights (term v), characterized by colder absolute temperatures (temperature feedback). The other terms cause a decrease of the relative humidity tendency by drying of the CBL by entrainment (term ii) (entrainment feedback), drying of the CBL by mass flux transport of moisture to the cloud layer (term iii) (drying feedback), heating of the CBL (term iv), and reduced mixed-layer-top cooling as the 

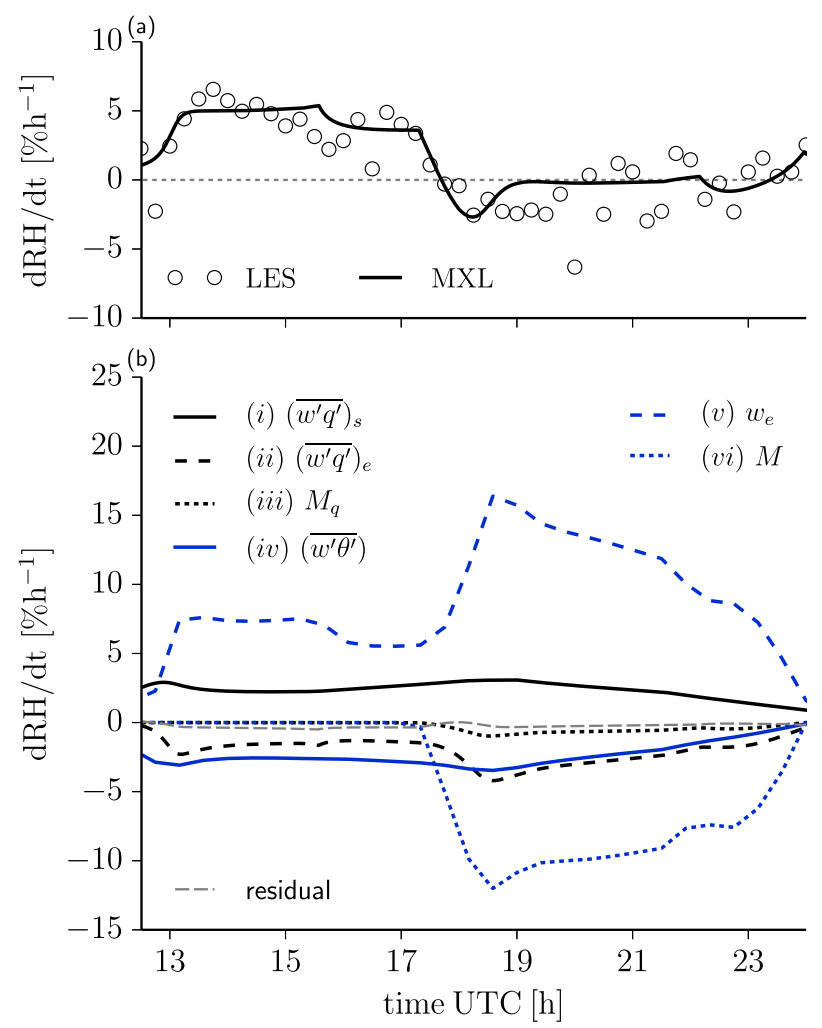

FIG. 9. (a) Temporal evolution of the mixed-layer-top relative humidity in both LES and MXL and (b) the absolute contribution of different processes on the relative humidity tendency in the mixed-layer model.

mass flux regulates the mixed-layer growth (term vi) (temperature feedback).

Figure $9 \mathrm{~b}$ shows the individual terms of Eq. (10). As this equation is derived with some approximations, we also included the residual tendency. The increase in $\mathrm{RH}_{h}$ because of surface exchange of moisture (term i) and decrease in $\mathrm{RH}_{h}$ due to mixed-layer heating (term iv) balance each other throughout the day. The resulting net tendency is less than $1 \% \mathrm{~h}^{-1}$. In the morning $\mathrm{RH}_{h}$ increases as the mixed-layer grows (term v), until the first clouds are formed. Next, mass flux transport initiates the sequence of feedbacks as described in section 2 . First, the mass flux rapidly decreases the mixed-layer growth. This reduces the related net tendency of $\mathrm{RH}_{h}$ from $5 \% \mathrm{~h}^{-1}$ at $1900 \mathrm{UTC}$ to $1 \% \mathrm{~h}^{-1}$ at 2300 UTC. As a result of the reduced mixed-layer growth, the tendency of the mixed-layer-top jumps decreases (Fig. 6), which enhances entrainment (term v) and therefore the entrainment of dry air (term i). Combined with the mass flux transport of moisture (term iii), dry-air entrainment counteracts the remaining positive tendency of $\mathrm{RH}_{h}$.

Although the relative humidity remains approximately constant toward the end of the experiment, the
$\mathrm{SCu}$ fraction (cloud core; Fig. 5) decreases as turbulence, driven by the surface buoyancy flux, decays in the afternoon transition. This indicates that $\mathrm{RH}_{h}$, often used as an indicator for $\mathrm{SCu}$ convection (e.g., Ek and Mahrt 1994; Ek and Holtslag 2004), does not fully reflect the potential of $\mathrm{SCu}$ occurrence. With additional knowledge of the mixed-layer-top variance, Eq. (4) provides a useful extension to predict or analyze the potential of $\mathrm{SCu}$.

\section{Conclusions}

This study investigated the processes and feedbacks associated with the mass flux of shallow cumulus ( $\mathrm{SCu})$ convection over land, combining results obtained with a mixed-layer model and large-eddy simulation (LES). The numerical experiments in LES are based on three observational cases of SCu over land: ARM, SCMS, and GoMACCS. We first described the feedbacks introduced by $\mathrm{SCu}$ convection, and their influence on the development of the subcloud-layer characteristics, by designing a conceptual diagram. The four main feedback loops, driven by the mass flux and all negative, regulate cloud formation and the subcloud layer development by adjusting (i) the mixed-layer-top moisture variance, (ii) mixed-layer-top temperature, (iii) mixedlayer moisture content, and (iv) the mixed-layer-top entrainment rate. Compared to clear boundary layers, the mass flux causes a decrease in mixed-layer growth and mixed-layer moisture content and an increase in potential temperature.

Our conceptual diagram served as a road map to understand the transition from a clear to cloudy boundary layer and the subsequent role of the mass flux in regulating the subcloud-layer dynamics. Analysis of the LES data resulted in a refined parameterization for the mixed-layer-top cloud-core velocity and a measure relating the mixed-layer-top moisture variance to the moisture transport associated with the mass flux. These parameterizations allowed us to extend the mixed-layer model formulation of Tennekes and Driedonks (1981) and refine the mass flux representation of Neggers et al. (2006). Combined, this resulted in a (single layer) mixed-layer model, capable of reproducing the transition from clear to cloud-topped boundary layers. Next, this model was employed to quantify the strength and relevance of the four negative feedbacks for the ARM case. First, we showed that the mixed-layer model formulation with the newly developed mass flux parameterization compares satisfactorily with the mixed-layer height, potential temperature, moisture content, and cloud-core fraction observed in LES. Here, actively integrating the mass flux in the dynamics of the subcloud 
layer played a crucial role in the robustness and physical consistency of the model. Second, we did a sensitivity study on the initial mixed-layer potential temperature and moisture content and free-tropospheric lapse rates relative to the ARM case. The results indicated that the model produces satisfactory results for cases ranging from the dry CBL to fully developed SCu. Third, by extending and employing a tendency equation for the relative humidity at the mixed-layer top, the relevance of the individual feedbacks was studied in more depth. The main conclusion from this exercise was that the mass flux initiates the subsequent negative feedbacks and regulates the subcloud-layer development.

Our findings summarize the essential, first-order effects of SCu clouds on the well-mixed (subcloud)-layer development and provide a basic mathematical framework to study these effects in more detail for conditions with transient $\mathrm{SCu}$ convection over land. This better understanding of $\mathrm{SCu}$ convection enables us to quantify how the dynamics and scalar budgets are modified in the subcloud layer. It is important to stress that our modeling framework opens new possibilities to study the influence of $\mathrm{SCu}$ in a conceptual manner by extending previous work on the dry CBL using the mixed-layer model. For example, our study showed that the direct influence of mass flux transport on the moisture budget is relatively small compared to other processes but still needs to be taken into account to understand and close the moisture budget in the subcloud layer. Similar transport processes could have an impact on the budgets of other scalars and chemical reactants, which is studied in more detail in a companion research conducted by Ouwersloot et al. (2014). Also, the feedback diagram and our modeling results indicate that $\mathrm{SCu}$ convection results in both drying and heating of the mixed layer. When coupled to a land surface scheme, this could enhance evaporation and thus influence the surface energy balance (van Heerwaarden et al. 2009). Finally, for studies using the mixed-layer-top relative humidity (or lifting condensation level) as an indicator for cloud formation (e.g., Ek and Mahrt 1994; Zhu and Albrecht 2002; Vilà-Guerau de Arellano 2007), our modeling framework might be beneficial as it actively accounts for the influence of the mixed-layer-top moisture variability on the formation of clouds and the influence of clouds on the relative humidity itself.

Acknowledgments. The authors acknowledge the helpful discussions with Roel Neggers during the early stages of this study and comments by Linda Schlemmer and three anonymous reviewers. The LES experiments were sponsored by the National Computing Facilities Foundation (NCF-NWO, Project SG132, SH-060-13).

\section{APPENDIX A}

\section{Derivation Mixed-Layer Model with Shallow Cumulus}

This appendix describes the derivation of the mixedlayer budget equations in the presence of shallow cumulus, using the specific humidity and therefore the budget of moisture as an example. We can define the total amount of moisture $M_{m}$ contained within the mixed layer with horizontal area $A_{T}$ and (constant) density $\rho$ as

$$
M_{m}=\rho A_{T} h\langle q\rangle,
$$

with the input of moisture at the surface $F_{s}$ and mixedlayer top $F_{h}$ :

$$
\begin{aligned}
& F_{s}=\rho A_{T}\left(\overline{w^{\prime} q^{\prime}}\right)_{s}, \\
& F_{h}=\rho\left(A_{T^{w}} w_{\mathrm{FT}}-A_{\mathrm{cc}} w_{\mathrm{cc}} q_{\mathrm{cc}}\right) .
\end{aligned}
$$

The term $F_{h}$ is the combined result of entraining air with free-tropospheric conditions $q_{\mathrm{FT}}$ with velocity $w_{e}$, and the local transport of air $q_{\mathrm{cc}}$ by the cloud core (area $\left.A_{\mathrm{cc}}\right)$ with velocity $w_{\mathrm{cc}}$ into the cloud layer. Combining the time derivative of Eq. (A1) with Eqs. (A2) and (A3), and dividing by $\rho A_{T}$, results in

$h \frac{d\langle q\rangle}{d t}+\langle q\rangle \frac{d h}{d t}=\left(\overline{w^{\prime} q^{\prime}}\right)_{s}+w_{e} q_{\mathrm{FT}}-\frac{A_{\mathrm{cc}}}{A_{T}} w_{\mathrm{cc}} q_{\mathrm{cc}}$.

With $A_{\mathrm{cc}} / A_{T}=a_{\mathrm{cc}}$ (fractional cloud-core coverage), $a_{\mathrm{cc}} w_{\mathrm{cc}}=M$ (mass flux), and $d h / d t=w_{e}-M$, Eq. (A4) can be rewritten to

$\frac{d\langle q\rangle}{d t}=\frac{\left(\overline{w^{\prime} q^{\prime}}\right)_{s}+w_{e}\left(q_{\mathrm{FT}}-\langle q\rangle\right)-M\left(q_{\mathrm{cc}}-\langle q\rangle\right)}{h}$.

With $q_{\mathrm{FT}}-\langle q\rangle=\Delta q$, this yields the well-known mixed-layer equation with the addition of transport of shallow cumulus.

\section{APPENDIX B}

\section{Case Descriptions}

All LES experiments were performed with DALES (Heus et al. 2010) using the Deardorff [prognostic subgrid scale turbulent kinetic energy (TKE)] subgrid-scale closure and a fifth (horizontal)-/second (vertical)-order advection scheme for scalars, momentum, and TKE. Vertical profiles were obtained by horizontal averaging of the 3D fields and are sampled at a 60-s interval and time averaged every $900 \mathrm{~s}$. Conditionally sampled fields 
TABLE B1. Initial and boundary conditions used for the ARM case in MXL.

\begin{tabular}{lc}
\hline \multicolumn{1}{c}{ Description } & Value \\
\hline Mixed-layer height $h_{0}(\mathrm{~m})$ & 140 \\
Potential temperature $\langle\theta\rangle_{0}(\mathrm{~K})$ & 301.4 \\
Potential temperature jump $\Delta \theta_{0}(\mathrm{~K})$ & 0.4 \\
Specific humidity $\langle q\rangle_{0}\left(\mathrm{~g} \mathrm{~kg}^{-1}\right)$ & 15.3 \\
Specific humidity jump $\Delta q_{0}\left(\mathrm{~g} \mathrm{~kg}^{-1}\right)$ & -0.2 \\
Entrainment ratio of virtual heat $\beta(-)$ & 0.15 \\
Potential temperature lapse rate $\gamma_{\theta}\left(\mathrm{K} \mathrm{km}^{-1}\right)$ & \\
$z \leq 700 \mathrm{~m}$ & 3.4 \\
$z>700 \mathrm{~m}$ & 5.7 \\
Moisture lapse rate $\gamma_{q}\left(\mathrm{~g} \mathrm{~kg}^{-1} \mathrm{~km}^{-1}\right)$ & 0.6 \\
$z \leq 650 \mathrm{~m}$ & 2.0 \\
$700<z \leq 1300 \mathrm{~m}$ & 8.75 \\
$z>1300$ & \\
\hline
\end{tabular}

(cloud and cloud core) are defined and sampled following Siebesma et al. (2003).

\section{a. Atmospheric Radiation Measurement Southern Great Plains (ARM)}

\section{1) LARGE-EDDY SIMULATION}

The LES setup of the ARM case is based on the initial and boundary conditions provided by Brown et al. (2002) with minor modifications: (i) removal of the weak largescale forcings (advection of heat and moisture) and (ii) increase in resolution, resulting for all cases in a grid of $6400 \mathrm{~m} \times 6400 \mathrm{~m} \times 4400 \mathrm{~m}$ with $256 \times 256 \times 220$ grid points, with a total integration time of $50400 \mathrm{~s}$. The second experiment (ARM-clear) uses the exact same setup, only with the moisture profile uniformly reduced by $7.5 \mathrm{~g} \mathrm{~kg}^{-1}$. The additional sensitivity experiments are constructed in a similar manner, following Table B2-that is, by adding a fixed offset over the entire vertical profiles $(\mathrm{A}-\mathrm{C})$ or skewing them with a certain factor (D-F).

\section{2) MIXED-LAYER MODEL}

To prevent the LES spinup from disturbing the comparison and to provide a shallow well-mixed layer to the mixed-layer model, the initial conditions for the conceptual model are based on the LES results after $1 \mathrm{~h}$, as summarized in Table B1. Boundary conditions, like the surface fluxes, are linearly interpolated from the values provided by Brown et al. (2002). The modifications for the ARM-clear and sensitivity studies are summarized in Table B2. Case ARM-nc is performed with the setup described in Table B1, with $M$ (and, consequently, $M_{\phi}$ ) set to zero.

\section{b. Small Cumulus Microphysics Case (SCMS)}

The LES setup of the SCMS case is based on the initial and boundary conditions provided by Neggers et al.
TABLE B2. Alterations to the ARM case (Table B1); $\mathcal{R}$ refers to the reference value from Table B1.

\begin{tabular}{ccccc}
\hline \hline Case & $\langle\theta\rangle_{0}(\mathrm{~K})$ & $\langle q\rangle_{0}\left(\mathrm{~g} \mathrm{~kg}^{-1}\right)$ & $\gamma_{\theta}\left(\mathrm{K} \mathrm{km}^{-1}\right)$ & $\gamma_{q}\left(\mathrm{~g} \mathrm{~kg}^{-1} \mathrm{~km}^{-1}\right)$ \\
\hline ARM-clear & $\mathcal{R}$ & 7.8 & $\mathcal{R}$ & $\mathcal{R}$ \\
(A) & $\mathcal{R}$ & 7.8 & $\mathcal{R}$ & $\mathcal{R}$ \\
(B) & 297 & 11.5 & $\mathcal{R}$ & $\mathcal{R}$ \\
(C) & 299.5 & 16.0 & $\mathcal{R}$ & $\mathcal{R}$ \\
(D) & $\mathcal{R}$ & $\mathcal{R}$ & $0.78 \mathcal{R}$ & $0.78 \mathcal{R}$ \\
(E) & $\mathcal{R}$ & $\mathcal{R}$ & $0.9 \mathcal{R}$ & $0.9 \mathcal{R}$ \\
(F) & $\mathcal{R}$ & $\mathcal{R}$ & $1.2 \mathcal{R}$ & $1.2 \mathcal{R}$
\end{tabular}

(2003, their Fig. 5). Although the SCMS campaign was conducted near the eastern coast of Florida and was therefore likely influenced by maritime conditions, we still consider it a continental case given its clear diurnal cycle in surface fluxes and SCu development. Like for the ARM case, the large-scale forcings (cooling tendency) are neglected, and a grid of $6400 \mathrm{~m} \times 6400 \mathrm{~m} \times$ $4000 \mathrm{~m}$ with $256 \times 256 \times 200$ grid points is used, with a total integration time of $43200 \mathrm{~s}$.

\section{c. Gulf of Mexico Atmospheric Composition and Climate Study (GoMACCS)}

The LES setup of the GoMACCS case is inspired by measurement data (sounding data and surface latent and sensible heat fluxes) from 11 September 2006, obtained during the GoMACCS campaign (Angevine et al. 2010). As its name implies, the campaign took place near the Gulf of Mexico (Houston). However, for similar reasons as for the SCMS case, we consider it as a continental case. A grid of $6400 \mathrm{~m} \times 6400 \mathrm{~m} \times 5000 \mathrm{~m}$ with $256 \times 256 \times 200$ grid points is used, with a total integration time of $43200 \mathrm{~s}$. The initial vertical profiles are summarized in Table B3 (intermediate values are linearly interpolated). For simplicity, the weak horizontal winds are set to zero, creating a free-convective case. The surface heat $\left(\mathrm{K} \mathrm{m} \mathrm{s}^{-1}\right)$ and moisture $\left(\mathrm{g} \mathrm{kg}^{-1} \mathrm{~m} \mathrm{~s}^{-1}\right)$ fluxes are introduced as

$$
\left(\overline{w^{\prime} \theta^{\prime}}\right)_{s}=0.13 \sin \left(\pi \frac{t}{t_{\text {sim }}}\right),
$$

TABLE B3. Description of the initial LES profiles for the GoMACCS case.

\begin{tabular}{rrrc}
\hline \hline$z(\mathrm{~m})$ & $\theta_{l}(\mathrm{~K})$ & $q_{t}\left(\mathrm{~g} \mathrm{~kg}^{-1}\right)$ & $\{u, v\}\left(\mathrm{m} \mathrm{s}^{-1}\right)$ \\
\hline 0 & 300.3 & 18.3 & $\{0,0\}$ \\
400 & 300.3 & 18.3 & $\{0,0\}$ \\
750 & 303.7 & 14.4 & $\{0,0\}$ \\
1750 & 305.7 & 12.9 & $\{0,0\}$ \\
2200 & 308.3 & 10.7 & $\{0,0\}$ \\
5000 & 322.3 & 2.3 & $\{0,0\}$ \\
\hline
\end{tabular}




$$
\left(\overline{w^{\prime} q^{\prime}}\right)_{s}=14.5 \sin \left(\pi \frac{t}{t_{\mathrm{sim}}}\right)
$$

where $t$ is the simulation time (s) and $t_{\text {sim }}$ is the maximum simulation time of $43200 \mathrm{~s}$.

\section{APPENDIX C}

\section{Relative Humidity Tendency Equation: Parameters}

Following Ek and Mahrt (1994) and Chang and Ek (1996), the parameters $C_{0}, C_{1}^{*}$, and $C_{2}^{*}$ of Eq. (10) are defined as

$$
\begin{aligned}
& C_{0}=\frac{1}{h \bar{q}_{s ; h}}, \\
& C_{1}^{*}=C_{0}\left[1+\left(\frac{L_{v}}{T R_{v}}-1\right)^{-1}\right] \mathrm{RH}_{h} \frac{d \bar{q}_{s ; h}}{d T}\left(\frac{p}{p_{s}}\right)^{R_{d} / c_{p}}, \\
& C_{2}^{*}=C_{0}\left[1-\left(\frac{c_{p}}{R_{d}}-1\right)\left(\frac{L_{v}}{T R_{v}}-1\right)^{-1}\right] \mathrm{RH}_{h} \frac{d \bar{q}_{s ; h}}{d T} \frac{g}{c_{p}},
\end{aligned}
$$

where $T$ and $p$ are the absolute mixed-layer-top temperature and pressure, $p_{s}$ is the surface pressure, $R_{d}$ is the gas constant for dry air, $R_{v}$ is the gas constant for moist air, $c_{p}$ is the specific heat of air at constant pressure, $g$ is the gravitational acceleration, and $L_{v}$ is the latent heat release of vaporization.

\section{REFERENCES}

Albrecht, B. A., A. K. Betts, W. H. Schubert, and S. K. Cox, 1979: Model of the thermodynamic structure of the trade-wind boundary layer: Part I. Theoretical formulation and sensitivity tests. J. Atmos. Sci., 36, 73-89.

Angevine, W. M., H. Jiang, and T. Mauritsen, 2010: Performance of an eddy diffusivity-mass flux scheme for shallow cumulus boundary layers. Mon. Wea. Rev., 138, 2895-2912.

Betts, A. K., 1973: Non-precipitating convection and its parameterization. Quart. J. Roy. Meteor. Soc., 99, 178-196.

, 2000: Idealized model for equilibrium boundary layer over land. J. Hydrometeor., 1, 507-523.

— , and W. Ridgway, 1989: Climatic equilibrium of the atmospheric convective boundary layer over a tropical ocean. J. Atmos. Sci., 46, 2621-2641.

- , and J. C. Chiu, 2010: Idealized model for changes in equilibrium temperature, mixed layer depth, and boundary layer cloud over land in a doubled $\mathrm{CO}_{2}$ climate. J. Geophys. Res., 115, D19108, doi:10.1029/2009JD012888.

Brown, A. R., and Coauthors, 2002: Large-eddy simulation of the diurnal cycle of shallow cumulus convection over land. Quart. J. Roy. Meteor. Soc., 128, 1075-1093.
Bunker, A. F., 1952: Measurements of the vertical water vapor transport and distribution within unstable atmospheric ground layers and the turbulent mass exchange coefficient. MIT/ WHOI Papers in Physical Oceanography and Meteorology, Vol. XII, No. 3, 42 pp.

Carson, D. J., 1973: The development of a dry inversion-capped convectively unstable boundary layer. Quart. J. Roy. Meteor. Soc., 99, 450-467.

Chang, S., and M. Ek, 1996: Note on "Daytime evolution of relative humidity at the boundary layer top." Mon. Wea. Rev., 124, 1323-1326.

Conzemius, R., and E. Fedorovich, 2007: Bulk models of the sheared convective boundary layer: Evaluation through large eddy simulations. J. Atmos. Sci., 64, 786-807.

Cuijpers, J., and P. Bechtold, 1995: A simple parameterization of cloud water related variables for use in boundary layer models. J. Atmos. Sci., 52, 2486-2490.

de Bruin, H. A. R., 1983: A model for the Priestley-Taylor parameter $\alpha$. J. Climate Appl. Meteor., 22, 572-578.

Ek, M., and L. Mahrt, 1994: Daytime evolution of relative humidity at the boundary layer top. Mon. Wea. Rev., 122, 2709-2721.

— , and A. A. M. Holtslag, 2004: Influence of soil moisture on boundary layer cloud development. J. Hydrometeor., $\mathbf{5}$, 86-99.

Emmitt, G. D., 1978: Tropical cumulus interaction with and modification of the subcloud region. J. Atmos. Sci., 35, 14851502.

Findell, K. L., and E. A. B. Eltahir, 2003: Atmospheric controls on soil moisture-boundary layer interactions. Part I: Framework development. J. Hydrometeor., 4, 552-569.

Gentine, P., A. K. Betts, B. R. Lintner, K. L. Findell, C. C. van Heerwaarden, and F. D. Andrea, 2013: A probabilistic bulk model of coupled mixed layer and convection. Part II: Shallow convection case. J. Atmos. Sci., 70, 1557-1576.

Grant, A. L. M., 2001: Cloud-base fluxes in the cumulus-capped boundary layer. Quart. J. Roy. Meteor. Soc., 127, 407-421.

— 2006: The cumulus-capped boundary layer. II: Interface fluxes. Quart. J. Roy. Meteor. Soc., 132, 1405-1422.

—, and A. P. Lock, 2004: The turbulent kinetic energy budget for shallow cumulus convection. Quart. J. Roy. Meteor. Soc., 130, 401-422.

Heus, T., and Coauthors, 2010: Formulation of and numerical studies with the Dutch Atmospheric Large-Eddy Simulation (DALES). Geosci. Model Dev. Discuss., 3, 99-180.

Lilly, D., 2002: Entrainment into mixed layers. Part I: Sharp-edged and smoothed tops. J. Atmos. Sci., 59, 3340-3352.

Neggers, R. A. J., P. G. Duynkerke, and S. M. A. Rodts, 2003 : Shallow cumulus convection: A validation of large-eddy simulation against aircraft and Landsat observations. Quart. J. Roy. Meteor. Soc., 129, 2671-2696.

— A. P. Siebesma, G. Lenderink, and A. A. M. Holtslag, 2004: An evaluation of mass flux closures for diurnal cycles of shallow cumulus. Mon. Wea. Rev., 132, 2525-2538.

_ B. Stevens, and J. Neelin, 2006: A simple equilibrium model for shallow-cumulus-topped mixed layers. Theor. Comput. Fluid Dyn., 20, 305-322.

,-- , and,- 2007 : Variance scaling in shallow-cumulustopped mixed layers. Quart. J. Roy. Meteor. Soc., 133, 16291641.

Nicholls, S., and M. A. LeMone, 1980: The fair weather boundary layer in GATE: The relationship of subcloud fluxes and structure to the distribution and enhancement of cumulus clouds. J. Atmos. Sci., 37, 2051-2067. 
Ouwersloot, H. G., and Coauthors, 2012: Characterization of a boreal convective boundary layer and its impact on atmospheric chemistry during HUMPPA-COPEC-2010. Atmos. Chem. Phys., 12, 9335-9353.

_ J. Vilà-Guerau de Arellano, B. J. H. van Stratum, M. C. Krol, and J. Lelieveld, 2014: Quantifying the transport of subcloud layer reactants by shallow cumulus clouds over the Amazon. J. Geophys. Res., 118, 13 041-13 059, doi:10.1002/ 2013JD020431.

Siebesma, A. P., and Coauthors, 2003: A large eddy simulation intercomparison study of shallow cumulus convection. $J$. Atmos. Sci., 60, 1201-1219.

_ , P. M. M. Soares, and J. Teixeira, 2007: A combined eddydiffusivity mass-flux approach for the convective boundary layer. J. Atmos. Sci., 64, 1230-1248.

Stevens, B., 2006: Bulk boundary-layer concepts for simplified models of tropical dynamics. Theor. Comput. Fluid Dyn., 20 (5-6), 279-304.

_ 2007: On the growth of layers of nonprecipitating cumulus convection. J. Atmos. Sci., 64, 2916-2931.

- and S. Bony, 2013: What are climate models missing? Science, 340, $1053-1054$.

_ a strong inversion. J. Atmos. Sci., 58, 1870-1891.

Stokes, G. M., and S. E. Schwartz, 1994: The Atmospheric Radiation Measurement (ARM) Program: Programmatic background and design of the cloud and radiation test bed. Bull. Amer. Meteor. Soc., 75, 1201-1221.

Stull, R. B., 1985: A fair-weather cumulus cloud classification scheme for mixed-layer studies. J. Climate Appl. Meteor., 24, 49-56.

—_, 1988: An Introduction to Boundary Layer Meteorology. Kluwer Academic Publishers, 670 pp.

Tennekes, H., 1973: A model for the dynamics of the inversion above a convective boundary layer. J. Atmos. Sci., 30, 558-567.
, and A. G. M. Driedonks, 1981: Basic entrainment equations for the atmospheric boundary layer. Bound.-Layer Meteor., 20, 515-531.

van Heerwaarden, C. C., J. Vilà-Guerau de Arellano, A. F. Moene, and A. A. M. Holtslag, 2009: Interactions between dry-air entrainment, surface evaporation and convective boundarylayer development. Quart. J. Roy. Meteor. Soc., 135, 1277-1291.

van Stratum, B. J. H., and Coauthors, 2012: Case study of the diurnal variability of chemically active species with respect to boundary layer dynamics during DOMINO. Atmos. Chem. Phys., 12, 5329-5341.

vanZanten, M., and Coauthors, 2011: Controls on precipitation and cloudiness in simulations of trade-wind cumulus as observed during RICO. J. Adv. Model. Earth Syst., 3, M06001, doi:10.1029/2011MS000056.

Vilà-Guerau de Arellano, J., 2007: Role of nocturnal turbulence and advection in the formation of shallow cumulus over land. Quart. J. Roy. Meteor. Soc., 133, 1615-1627.

_ E. G. Patton, T. Karl, K. van den Dries, M. C. Barth, and J. J. Orlando, 2011: The role of boundary layer dynamics on the diurnal evolution of isoprene and the hydroxyl radical over tropical forests. J. Geophys. Res., 116, D07304, doi:10.1029/ $2010 J D 014857$.

, C. C. van Heerwaarden, and J. Lelieveld, 2012: Modelled suppression of boundary-layer clouds by plants in a $\mathrm{CO}_{2}$-rich atmosphere. Nat. Geosci., 5, 701-704.

Warren, S. G., and C. J. Hahn, cited 2010: Climatic atlas of clouds over land and ocean. [Available online at http://www.atmos. washington.edu/CloudMap/index.html.]

Willmott, C. J., 1981: On the validation of models. Phys. Geogr., 2 , 184-194.

Zhu, P., and B. Albrecht, 2002: A theoretical and observational analysis on the formation of fair-weather cumuli. J. Atmos. Sci., 59, 1983-2005. 


\title{
CORRIGENDUM
}

\author{
BART J. H. VAN STRATUM
}

Max Planck Institute for Meteorology, Hamburg, Germany

JORDI VILÀ-GUERAU DE ARELLANO

Meteorology and Air Quality Section, Wageningen University, Wageningen, Netherlands

Chiel C. van HeERwaArden

Max Planck Institute for Meteorology, Hamburg, Germany

HuUg G. OUWERSLOOT

Max Planck Institute for Chemistry, Mainz, Germany

(Manuscript received and in final form 9 January 2015)

In appendix B, section c of van Stratum et al. (2014), two errors were introduced in the case description of the Gulf of Mexico Atmospheric Composition and Climate Study (GoMACCS) case. To ensure reproducibility and consistency with Fig. 4 of van Stratum et al. (2014), we propose the following amendment. The corrected surface moisture flux and input sounding, as used in the large-eddy simulation (LES) experiments, are provided in Eq. (1) [Eq. (B2) in van Stratum et al. 2014] and Table 1 (Table B3 in van Stratum et al. 2014), respectively:

$$
\left(\overline{w^{\prime} q^{\prime}}\right)_{s}=14.5 \times 10^{-2} \sin \left(\pi \frac{t+a_{1}}{t_{\mathrm{sim}}+a_{2}}\right),
$$

with $\left(\overline{w^{\prime} q^{\prime}}\right)_{s}$ in $\mathrm{g} \mathrm{kg}^{-1} \mathrm{~m} \mathrm{~s}^{-1}, t$ the simulation time (s), $t_{\text {sim }}$ the total simulation time (43200 s), $a_{1}=1800 \mathrm{~s}$, and $a_{2}=3000 \mathrm{~s}$.

Acknowledgments. The authors thank Martin Sikma for his careful assessment of our paper and reporting the discrepancies between the paper and LES setup.

\section{REFERENCE}

van Stratum, B. J. H., J. Vilà-Guerau de Arellano, C. C. van Heerwaarden, and H. G. Ouwersloot, 2014:

Subcloud-layer feedbacks driven by the mass flux of shallow cumulus convection over land. J. Atmos. Sci., 71, 881-895, doi:10.1175/JAS-D-13-0192.1.

Corresponding author address: Bart van Stratum, Max Planck Institute for Meteorology, Bundesstraße 53, 20146 Hamburg, Germany. E-mail: bart.vanstratum@mpimet.mpg.de 
TABLE 1. Description of the initial LES profiles for the GoMACCS case.

\begin{tabular}{cccc}
\hline \hline $\begin{array}{c}z \\
(\mathrm{~m})\end{array}$ & $\begin{array}{c}\theta_{l} \\
(\mathrm{~K})\end{array}$ & $\begin{array}{c}q_{t} \\
\left(\mathrm{~g} \mathrm{~kg}^{-1}\right)\end{array}$ & $\begin{array}{c}\{u, v\} \\
\left(\mathrm{m} \mathrm{s}^{-1}\right)\end{array}$ \\
\hline 0 & 300.3 & 18.3 & $\{0,0\}$ \\
387.5 & 300.3 & 18.3 & $\{0,0\}$ \\
637.5 & - & 14.55 & $\{0,0\}$ \\
837.5 & 303.95 & - & $\{0,0\}$ \\
1737.5 & 305.7 & 12.9 & $\{0,0\}$ \\
1887.5 & 306.8 & - & $\{0,0\}$ \\
2187.5 & 308.3 & 10.65 & $\{0,0\}$ \\
5000 & 322.3 & 2.2 & $\{0,0\}$ \\
\hline
\end{tabular}

